\title{
EVIDENCE OF INTERGRADATION WITHIN THE GOLDEN-CHEEKED WOODPECKER
}

\author{
DESMOND SIEBURTH, DEVON A. DERAAD, and JAMES M. MALEY, Moore \\ Laboratory of Zoology, Occidental College, 1600 Campus Road, Los Angeles, Cali- \\ fornia 90041; jmaley@oxy.edu
}

The Golden-cheeked Woodpecker (Melanerpes chrysogenys), restricted to the Pacific slope of Mexico from Sinaloa to Oaxaca, comprises two subspecies. Nominate M. c. chrysogenys, identified by its extensively red crown, ranges from Sinaloa south to San Blas, Nayarit (Winkler and Christie 2017). Ridgway (1914) stated that near San Blas there is an abrupt transition from the reddish-naped $M$. c. chrysogenys to the yellow-naped M. c. flavinuchus, which is distributed southward to western Oaxaca. The subspecies also differ in the amount of yellow in the face, with flavinuchus averaging less yellow; this subspecies is also generally paler overall (Ridgway 1914). The distinction between these two subspecies, however, is perhaps not widely appreciated. For example, geographic variation in the crown pattern of the Golden-cheeked Woodpecker was not mentioned by Howell and Webb (1995), who illustrated only flavinuchus. The question of intergradation between the two subspecies has not been addressed in the literature previously. Therefore, we investigated it by evaluating 172 specimens in the collection of the Moore Laboratory of Zoology (MLZ), 14 specimens in the Natural History Museum of Los Angeles County (LACM), five specimens in the Dickey Bird and Mammal Collection of the University of California, Los Angeles (UCLA), and 31 specimens in the Western Foundation of Vertebrate Zoology (WFVZ), Camarillo, California.

In this species, males are larger than females in both wing chord and culmen (Table 1 ). The differences in both variables are significant $(p<<0.001)$, so we analyzed differences between the subspecies in the two sexes separately. Measurements confirmed that in both sexes M. c. flavinuchus averages larger than M. c. chrysogenys in both features (Table 1). The specimens analyzed for variation in size exclude any from Nayarit, since that state contains the zone of contact. The difference in males was significant for wing chord $(p=0.008)$ but not for culmen length $(p=0.37)$. The difference in females was significant for both wing chord and culmen length $(p<0.001)$.

Visual inspection confirmed that $M$. c. flavinuchus has a yellow nape while $M$. c. chrysogenys has a reddish-orange nape. In 25 specimens of $M$. c. chrysogenys from Sinaloa the length of the crown patch averages $32.9 \mathrm{~mm}$ (range 22.3-37.4 $\mathrm{mm}$, standard error 0.88 ), whereas in 74 of M. c. flavinuchus collected from Jalisco to Oaxaca it averages $24.5 \mathrm{~mm}$ (range 17.1-32.8 mm). According to a $t$ test this difference is highly significant $(p<<0.01)$. Although Ridgway did not mention any phenotypic intermediates, we found that of the 20 specimens from Nayarit housed in the MLZ, 19 have a nape color between reddish-orange and yellow, suggesting intergradation (MLZ:Bird: 28042-28045, 28533-28535, 41948, 41957, 41973, 41978, 47952-47954, 47956, 47961, 58244-58246). These specimens with intermediate nape color, collected by Chester C. Lamb across the entire state of Nayarit between 1937 and 1950, represent an apparently wide contact zone (Figure 1). Intermediate specimens were collected as far north as near Acaponeta $\left(22.5^{\circ} \mathrm{N}\right.$, $105.4^{\circ} \mathrm{W}$ ), many in the San Blas area, and another series of intermediates in northwestern Jalisco near Puerto Vallarta. That San Blas is in the area of intermediacy, as well as a focus for ornithology and birding along Mexico's Pacific coast, has likely contributed to the neglect of geographic variation in the Golden-cheeked Woodpecker.

These specimens of intermediate plumage from the transition zone between the subspecies chrysogenys and flavinuchus raise questions about the extent of historic and current gene flow between the two populations. The transition between the 


\section{NOTES}

Table 1 Variation in Size by Sex and Subspecies in the Golden-cheeked Woodpecker ${ }^{a}$

\begin{tabular}{|c|c|c|}
\hline & Males & Females \\
\hline $\begin{array}{l}\text { Subspecies pooled } \\
\text { n }\end{array}$ & 91 & 98 \\
\hline \multicolumn{3}{|l|}{ Wing chord } \\
\hline range & $109.4-129.3$ & $109.6-130.4$ \\
\hline standard error & 0.34 & 0.36 \\
\hline \multicolumn{3}{|l|}{ Culmen } \\
\hline mean & 25.2 & 23.3 \\
\hline range & $22.1-27.9$ & $21.0-26.9$ \\
\hline standard error & 0.15 & 0.12 \\
\hline \multicolumn{3}{|l|}{ M. c. flavinuchus } \\
\hline$n$ & 68 & 75 \\
\hline \multicolumn{3}{|l|}{ Wing chord } \\
\hline mean & 121.3 & 118.8 \\
\hline range & $112.5-129.3$ & $109.6-130.4$ \\
\hline standard error & 0.38 & 0.42 \\
\hline \multicolumn{3}{|l|}{ Culmen } \\
\hline mean & 25.4 & 23.47 \\
\hline range & $22.5-29.1$ & $21.0-26.9$ \\
\hline standard error & 0.16 & 0.15 \\
\hline \multicolumn{3}{|l|}{ M. c. chrysogenys } \\
\hline$n$ & 17 & 17 \\
\hline \multicolumn{3}{|l|}{ Wing chord } \\
\hline mean & 118.8 & 116.2 \\
\hline range & 109.4-123.0 & $112.2-122.2$ \\
\hline standard error & 0.78 & 0.56 \\
\hline \multicolumn{3}{|l|}{ Culmen } \\
\hline mean & 25.1 & 22.7 \\
\hline range & $22.1-23.9$ & $21.9-23.9$ \\
\hline standard error & 0.38 & 0.14 \\
\hline
\end{tabular}

${ }^{a}$ Specimens from Nayarit, in the zone of intergradation between the two subspecies, excluded.

subspecies in Nayarit occurs where the Pacific coastal plain is interrupted by the Trans-Mexican Volcanic Belt, which acts as a biogeographic barrier to gene flow and distribution in many taxa (Howell and Webb 1995). Arbeláez-Cortés et al. (2014) found divergence in mitochondrial DNA between M. c. chrysogenys and M. c. flavinuchus but no differences across four nuclear loci, which suggests either considerable gene flow or recent divergence. We downloaded the gene sequences generated by Arbeláez-Cortés et al. (2014), available from GenBank, for the mitochondrial gene ND2 from samples of two individuals each of chrysogenys from Sinaloa (GenBank numbers: KF752976 and KF752977) and flavinuchus from Guerrero (GenBank numbers: KF752962 and KF752978) and used the program Geneious, version 8.0.5 (Biomatters, Auckland, New Zealand), to align them. Sequences were chosen away from the zone of intergradation. Our alignment indicated that the subspecies differ in 5 of the 463 base pairs of ND2. Neither we nor Arbeláez-Cortés et al. (2014) detected any other differences between the subspecies in this gene.

Our findings of phenotypic introgression, combined with equivocal evidence of intraspecific genetic divergence, make the Golden-cheeked Woodpecker a compelling 


\section{NOTES}

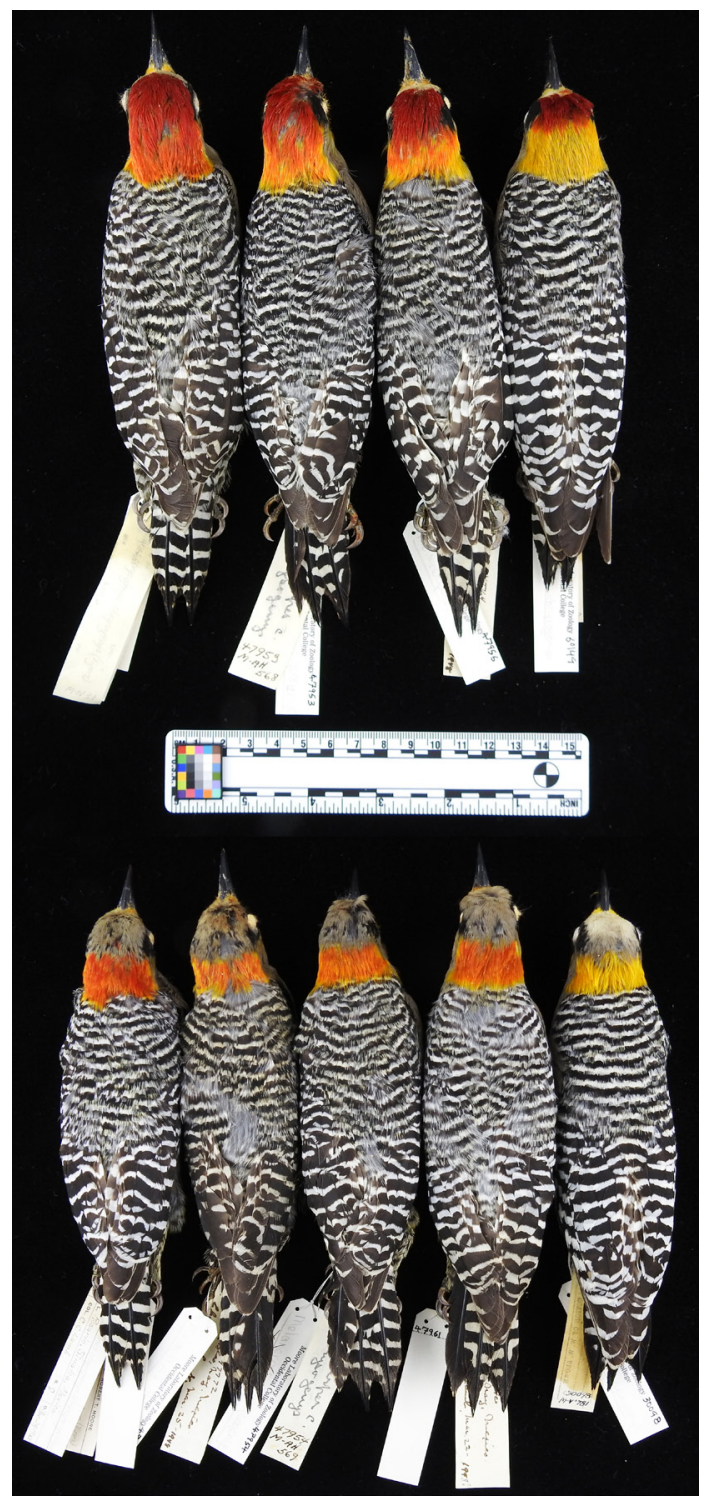

Figure 1. Specimens showing intergradation in nape color in the Golden-cheeked Woodpecker. Above, males, from left to right, MLZ 5911 (El Rosario, Sinaloa), 47953, 47956 (both San Blas, Nayarit), 30149 (Rincón, Guerrero). Below, females, from left to right, MLZ 5917 (El Rosario, Sinaloa), 47952, 47954, 47961 (these three San Blas, Nayarit), 30098 (Rincón, Guerrero). The specimens at the left end of each row are typical of $M$. c. chrysogenys, whereas those on the right ends are typical of M. c. flavinuchus. 


\section{NOTES}

species for further study, with possible implications for understanding intraspecific divergence across biogeographic barriers and updating our knowledge of the natural history of this Mexican endemic species.

We would like to thank the following collection managers for providing access to specimens: René Corado, Kimball Garrett, and Kathy Molina. We thank Daniel D. Gibson and Philip Unitt for their constructive reviews, which considerably improved the manuscript.

\section{LITERATURE CITED}

Arbeláez-Cortés, E., Milá, B., and Navarro-Sigüenza, A. G. 2014. Multilocus analysis of intraspecific differentiation in three endemic bird species from the northern neotropical dry forest. Mol. Phylogen. and Evol. 70:362-377.

Howell, S. N. G., and Webb, S. 1995. A Guide to the Birds of Mexico and Northern Central America. Oxford Univ. Press, Oxford, England.

Ridgway, R. 1914. The Birds of North and Middle America. Bull. U.S. Natl. Mus. 50 , part VI.

Winkler, H., and Christie, D. A. 2017. Woodpeckers (Picidae), in Handbook of the Birds of the World Alive (J. del Hoyo, A. Elliott, J. Sargatal, D. A. Christie, and E. de Juana, eds.). Lynx Edicions, Barcelona.

Accepted 15 September 2018 